\title{
La Gran Logia Bonaerense y su preocupación por la educación: Una de las fuentes del rito nacional español
}

\section{The Grand Lodge of Buenos Aires and its concern about education: One of the sources of the Spanish National Rite}

\begin{abstract}
Gabriel Darrigran Algaba
Investigador y ayudante de la cátedra de historia constitucional de la Universidad Nacional de La Plata, Argentina. Experto universitario en archivística y documentación masónica en la Universidad Nacional de Educación a Distancia, España. Correo electrónico: ordencorintio@gmail.com
\end{abstract}

DOI: http://dx.doi.org/10.15517/rehmlac.v9i1.28198

Fecha de recibido: 15 de marzo de 2017 - Fecha de aceptación: 22 de abril de 2017

Palabras clave

Masonería; Argentina; La Plata; España; Rito; Gran Logia Bonaerense; Gran Oriente Ibérico

\section{Keywords}

Freemasonry; Argentina; La Plata; Spain; Rite; Grand Lodge of Buenos Aires, Iberian Grand Orient

\section{Resumen}

Este texto pretende exponer una primera aproximación al proyecto pedagógico de una asociación masónica argentina poco conocida, surgida en un momento del siglo XIX de gran influencia del positivismo científico. La Gran Logia Bonaerense, uno de los productos de una ciudad planificada para ser una "ciudad modelo", que desde su creación buscó posicionarse como una alta casa de estudios, instruyendo a la clase obrera y a la media burguesía. Asimismo, se demuestra cómo, a través de las redes masónicas atlánticas, sus doctrinas lograron influir en España y cambiar parte de la estructura de la Gran Logia Simbólica Española y ser una de las fuentes del rito del Gran Oriente Ibérico.

\begin{abstract}
The main purpose of this text is an initial approach to the educational project of a little-known argentine masonic society, which arose in the $19^{\text {th }}$ century, and was highly influenced by the Scientific Positivism. The Grand Lodge of Buenos Aires, one of the results of a city planned to be a "Model City", which sought to be considered since its beginnings an Institute of Higher Learning, educating the working class and the lower middle class. Furthermore, we show, through the Atlantic Masonic Networks, how its doctrines succeeded in influencing Spain and changing part of the structure of the Symbolic Grand Lodge of Spain and therefore, is considered to be one of the sources of the Iberian Grand Orient Rite.
\end{abstract}




\section{Introducción}

Es sabido que el siglo XIX fue un siglo de importantes cambios; entre sus dos grandes revoluciones industriales, que transformaron occidente, se acuñaría el término "científico" para formar parte del léxico de la época y ser utilizado como un emblema de progreso y de modernidad. De forma generalizada, tanto los historiadores argentinos como los sudamericanos ignoran u omiten profundizar sobre la cuestión masónica del siglo XIX, como si no hubiera influido lo suficiente en la historia de los pueblos de la región. A lo largo de las décadas, distintas generaciones de inmigrantes y exiliados consolidaron redes civiles internacionales que sirvieron como medio de transferencia para prácticas sociales, culturales y políticas, entre las que se encontraban las prácticas masónicas. Estas, ocultas al común de la gente, se filtraban a la sociedad a través del librepensamiento y del laicismo enseñado en escuelas dominicales y talleres de oficios para la clase obrera.

Entre las prácticas masónicas encontramos los ritos que, para las ciencias sociales, lejos de ser sagrados e inamovibles, son flexibles, polisémicos y con una gran capacidad de adaptarse a los cambios sociales y a las ideologías de los grupos que los practican. Los ritos que dirigían y ordenaban a las ceremonias, detallados en los guiones de los rituales, reproducían gestos, palabras, símbolos y movimientos repetitivos con la finalidad de reforzar un sistema pedagógico-doctrinal determinado.

En la primera parte de este trabajo se verá cómo la combinación entre, una ciudad erigida en pleno auge del positivismo científico, un grupo de masones vinculados a la educación argentina, y una progresista ley de educación, provocará la aparición de un nuevo rito masónico cientificista en la región, que vendrá a subsanar las molestias de muchos masones argentinos, que consideraban que el catolicismo se había infiltrado en la masonería nacional.

Y en una segunda parte, demostraremos cómo la preocupación por la educación de los masones fundadores de la Gran Logia Provincial Bonaerense, institución que acogía en su seno el nuevo rito, logrará modernizar una de las asociaciones de la masonería española, según su proyecto educativo; propiciando una reconfiguración de su rito y llegándose a cambiar las normas de ingreso en los talleres, para adaptarlas a las doctrinas argentinas en materia de educación.

\section{La provincia de Buenos Aires faro del progreso sudamericano}

\section{Una ciudad racional}

Para comprender adecuadamente las características de la Gran Logia Bonaerense, es preciso analizar el contexto histórico y ámbito geográfico en que fue fundada esta corporación masónica. Hacia fines del siglo XIX la ciudad de Buenos Aires se convirtió en 
capital nacional y provincial, con la federalización ${ }^{1}$ de la ciudad en 1880 . Con esto terminó el largo proceso de organización y consolidación del Estado Nacional, requiriendo la provincia de Buenos Aires una nueva capital. A partir de este momento Argentina será dirigida por una elite gobernante que fue conocida como la "Generación del 80". Procedentes de familias adineradas de las provincias y de la capital, muchos de ellos masones, tuvieron a su cargo las más importantes funciones políticas, económicas, militares y religiosas, manteniéndose en el poder mediante el fraude electoral. Tendrán un pensamiento económico liberal y un pensamiento filosófico vinculado al positivismo sociológico, que planteaba que para lograr el progreso social se requería imponer el orden de la Nación. Esta generación intentará secularizar el Estado, separándolo de la Iglesia católica, como lo propusieron las leyes de secularización de cementerios, de registros civiles y educación común, laica, gratuita y obligatoria.

En ese momento la provincia de Buenos Aires representaba casi la totalidad del poder económico del Estado y el gobernador Rocha, masón e hijo de otro ${ }^{2}$, que había asumido el 1 de mayo de 1881, junto a sus colaboradores comprendieron la necesidad de que la provincia tuviera su propia capital. Descartando trasladar la capital provincial a otro municipio existente, se embarcó en el proyecto de una nueva ciudad con características nunca antes vistas, colocando su piedra fundacional el 19 de noviembre de $1882^{3}$. La nueva ciudad estaría a la vanguardia en los servicios públicos, siendo la primera en Latinoamérica en ser construida con alumbrado eléctrico y con un proyecto que incluía la creación de un nuevo puerto a tan solo 50 kilómetros del puerto de Buenos Aires ${ }^{4}$.

Estos hombres de la política, frecuentemente vinculados a la masonería, pensaban a la futura capital provincial como una ciudad ideal, en la cual el laicismo, la educación experimental y la formación de futuros ciudadanos librepensadores, serían sus marcas distintivas ${ }^{5}$; y efectivamente así lo fue, en sus primeros años, se tuvo la intencionalidad política de que La Plata sea una "ciudad modelo" para todo el continente latinoamericano, costara lo que costase. Dentro y fuera de las logias los masones platenses orientaron sus esfuerzos hacia la formación de los ciudadanos de la clase obrera fundando escuelas de

\footnotetext{
${ }^{1}$ Las confederaciones están compuestas por estados, provincias, regiones o cantones que gozan de un mayor o menor grado de autonomía pero que, a través de un pacto, delegan el ejercicio de su soberanía a un gobierno superior. En el caso argentino, la Constitución no declara cual es la capital de la Confederación Argentina, sino que dice que la debe determinar el Congreso Nacional previa cesión de la legislatura de la provincia o región. La Legislatura porteña se negaba a ceder su municipio para mantener el control del puerto y la aduana; cosa que provocó que la ciudad se levante en armas contra el Gobierno Nacional, costando 3.000 vidas y una cesión forzada en 1880 .

${ }^{2}$ Lappas, Alcibiades, La Masonería Argentina a través de sus hombres (Buenos Aires: Alcibiades Lappas, 1966), 335.

${ }^{3}$ AHPBA. La Plata. Ministerio de Gobierno. Año 1882. Leg. 15 Exp. 706/0.

${ }^{4}$ AHPBA. La Plata. Ministerio de Gobierno. Año 1883. Leg. 10 Exp. 825/1.

${ }^{5}$ César Arrondo, "Arquitectos y soñadores en los origenes de la ciudad de La Plata", en Nueva historia de las redes masonicas atlanticas: 200 años de relaciones masonicas entre Argentina, Uruguay, Chile y Francia, coord. Dévrig Mollés (La Plata: Edulp, 2012), 381.
} 
oficios, de formación ciudadana y de enseñanza primaria. Este progresismo, innato en la ciudad, despertaría la atención de la prensa liberal europea a los pocos meses de su fundación: "En la ciudad donde los palacios se destinan a escuelas, están completamente fuera de su sitio los conventos. Nada tienen que hacer en La Plata los frailes, porque lo que allí hay que hacer no es rezar, sino trabajar" 6 .

El 19 de mayo de 1882 el Departamento de Ingenieros de la provincia de Buenos Aires, había presentado al Poder Legislativo provincial un proyecto basado en una ciudad con una legua de frente sobre las lomas de la ensenada por 4.360 metros de fondo ${ }^{7}$ con un gran bosque de eucaliptos como acceso principal y ubicada a diez kilómetros del Rio de La Plata. Finalmente, el trazado será una obra de simetría y constó de un polígono regular de cuatro lados, dividido por una red de calles numeradas ${ }^{8}$ de dieciocho metros de ancho que se cortaban en ángulo recto, once avenidas de treinta metros paralelas a las anteriores y cuatro que las cortaban en $45^{\circ}$ formando un gran rombo central, aparte de dos grandes diagonales que comunicaban los extremos del polígono con el centro del trazado. La ciudad estaba delimitada por un boulevard de noventa metros de ancho que la circundaba; ésta poseía una gran plaza central circular, dos grandes parques en forma de rectángulos, uno en forma de octágono, y dieciocho plazas distribuidas simétricamente en forma de cuadrados, rectángulos, rombos, hexágonos y círculos. Su entorno también había sido planificado, al casco urbano lo rodearía una primera zona de chacras, a ésta una segunda zona de quintas $\mathrm{y}$, a ambas, una tercera zona de estancias, que finalmente terminará desvirtuándose a lo largo de las décadas.

La urbe estaría cruzada por un "eje monumental" donde se ubicarían los palacios y edificios públicos provinciales y municipales, junto a la catedral de estilo neogótico que se proyectó frente a la plaza principal. Las calles y manzanas de este eje administrativo fueron diseñadas previendo que tendrían mayor circulación que el resto, por tal motivo sus manzanas tenían un diámetro menor, ampliándose éstas a medida que se iban alejando del eje hasta llegar a los 120 metros de diámetro ${ }^{9}$. El proyecto urbanístico, con gran influencia racionalista, pronosticó el advenimiento del trasporte colectivo y las futuras formas de organización, siendo galardonado como "Ciudad del Futuro" en la exposición internacional de París de $1889^{10}$.

Se eligió un sistema reticulado de manzanas cuadradas y rectangulares para que la edificación civil fuese menos costosa y tuvieran espacios libres para jardines interiores que facilitaran la circulación del aire. Priorizando que las manzanas triangulares, producto de

\footnotetext{
${ }^{6}$ Las Dominicales del Libre Pensamiento, "Los frailes en La Plata", 4 de diciembre de 1886, 3.

${ }^{7}$ Antonio Salvadores, Fundación de la Ciudad de La Plata: Documentos éditos e inéditos (La Plata: Publicaciones del Archivo Histórico de la Provincia de Buenos Aires, 1932), LVI-LVII.

${ }^{8}$ Gracias a la numeración ordenada de las calles y su diseño simétrico, a través de un cálculo matemático se puede determinar a qué altura de la calle queda una determinada casa o local.

${ }^{9}$ Esta característica brinda al plano de la ciudad su simetría bilateral y de ampliación.

${ }^{10}$ AHPBA. La Plata. Ministerio de Gobierno. Año 1891. Leg. 13 Exp. 1185/0.
} 
las intersecciones de las calles y las diagonales que las cruzaban, fueran utilizadas para pequeñas plazas y edificios públicos que requerían fácil acceso.

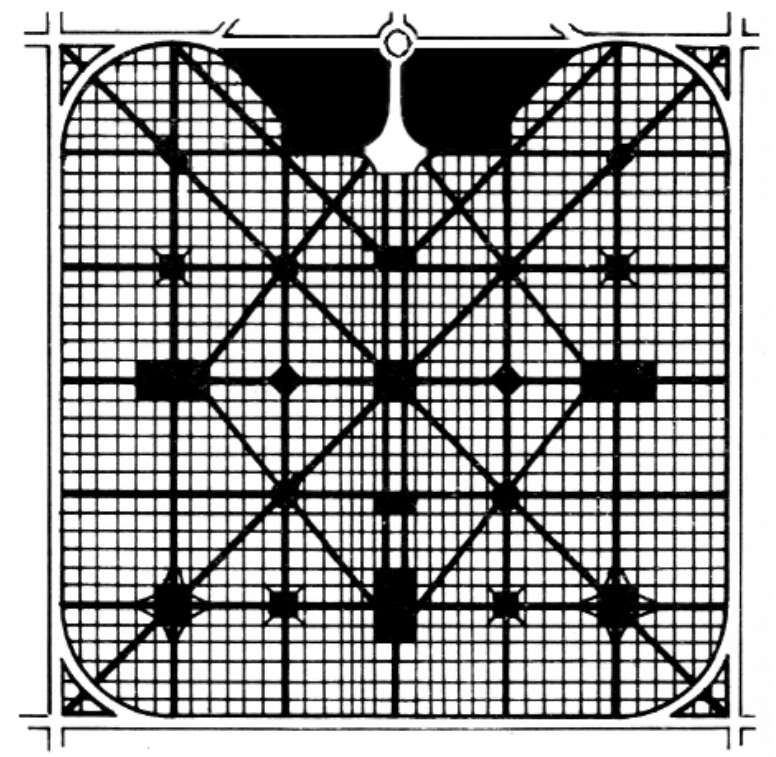

Esquema del plano fundacional de La Plata. Año 1882.

Podemos evidenciar la voluntad política de que la capital bonaerense sea, desde sus cimientos, una ciudad cosmopolita a través del diseño de los edificios públicos más importantes. Para ello se acordó un concurso internacional, con distintos premios. Las bases fueron redactadas en forma de avisos y traducidas al francés, inglés, italiano y alemán, siendo distribuidas en toda Europa y América. Al concurso se presentaron 27 proyectos representando a la República Argentina, Alemania, Bélgica, Francia e Inglaterra ${ }^{11}$. Dicho sea de paso, estos edificios públicos fueron orientados para que sus fachadas estuvieran de cara al Este, para recibir la mayor luz posible en el horario de mayor actividad. Otro de los productos de la voluntad política, fue el plan de construcción de edificios para la enseñanza primaria y media encargado por el gobierno de la provincia al arquitecto Carlos Altgelt, experto en arquitectura escolar, que solía contemplar en sus obras el programa académico que se desarrollaría en el edificio antes de proyectarlo ${ }^{12}$; y así es como se contó con edificaciones para la enseñanza perfectamente planificadas.

A partir de mediados del siglo XIX, se habían comenzado a conocer en el país las teorías que habían nacido como reacción a las ciudades industriales que crecieron desordenadamente desde fines de siglo XVIII. Reacciones de teóricos como los socialistas

\footnotetext{
${ }^{11}$ Salvadores, Fundación de la Ciudad de La Plata.

${ }^{12}$ Fernando Gandolfi y otros, "Los ámbitos de la memoria: Liceo Víctor Mercante", Ambiente, Revista de arquitectura, urbanismo y planificación 62 (1989): 22.
} 
utópicos o de quienes popularizaban sus ideas a través de la literatura, como Julio Verne ${ }^{13}$, quien influyó directamente entre aquellos que proyectaron la ciudad ${ }^{14}$. Producto de la nueva corriente de arquitectura y urbanismo higienista, pretendía diferenciarse de las congestionadas urbes europeas y de la poco aséptica Buenos Aires, gracias a las amplias zonas verdes regularmente establecidas cada seis manzanas y las importantes calles con que había sido creada.

En todo lo anterior nos encontramos con un denominador común vinculado al positivismo y al cientificismo que florecía a la par de la ciudad, éste es "la necesidad de claridad, de racionalidad, de rigor geométrico que facilite el trabajo". Es por esto que La Plata, debido a su planificación y construcción, es considerada la primera ciudad en el mundo en haberse erigido de acuerdo a las ideas republicanas, en pleno afianzamiento de la Revolución Industrial y la ciencia positivista. Y como sí esto fuera poco, los librepensadores que la planificaron dibujaron con sus diagonales el mítico emblema de la Francmasonería, como sello de identidad de la nueva capital de la provincia ${ }^{15}$.

Una vez expuesto el contexto histórico y territorial, y antes de continuar, conviene que nos detengamos muy brevemente en una aproximación a la evolución de la educación elemental argentina durante el siglo XIX, desde la sanción de la Constitución Nacional en 1853, hasta la Ley de Educación del año 1884, para dilucidar en qué "caldo de cultivo cultural" se fundó la asociación masónica que nos interesa exponer.

\section{Evolución de la enseñanza pública argentina}

Muchos años después de haberse superado la discusión entre monarquía o república de principios de siglo XIX, la generación conocida como del 37, que agrupaba a personalidades como Alberdi, Mitre y Sarmiento, construyó las bases ideológicas que formaron al país a partir de la batalla de Caseros ${ }^{16}$, que luego se consolidó con la batalla de Pavón ${ }^{17}$ y tuvo su máxima expresión con la Generación del 80.

La fuente directa de la Constitución Nacional de 1853 fue el proyecto de constitución en el anexo de la obra Bases y Puntos de Partida para la Organización Política de la República Argentina, publicada en Chile por Juan Bautista Alberdi, que

\footnotetext{
${ }^{13}$ Las crónicas de la época afirman que inmediatamente fue conocida como "una ciudad a lo Julio Verne", por haberse publicado en Francia, tan solo tres años antes, la obra Los Quinientos Millones de la Begún, en donde el escritor francés describe una ciudad ideal llamada France Ville con un trazado similar a La Plata.

${ }^{14}$ Salvadores, Fundación de la Ciudad de La Plata, 34.

${ }^{15}$ En el plano de la ciudad se observa una escuadra y un compás: La escuadra está formada por los diagonales $73,74,79$ y 80 ; y el compás por los diagonales 77 y 78 .

${ }^{16}$ Ocurrida en febrero de 1852, donde el ejército de la Confederación Argentina dirigido por Juan Manuel de Rosas, fue derrotado por el Ejército Grande, compuesto por fuerzas de Brasil, Uruguay y las provincias de Entre Ríos y Corrientes.

${ }^{17}$ De septiembre de 1861, en la que el ejército unitario de Buenos Aires dirigido por Mitre, vence definitivamente al de la Confederación, al mando de Urquiza. Significó el fin de la Confederación Argentina y posicionó a Buenos Aires como potencia dominante en el país.
} 
sintetizaba los deseos de occidentalización de los argentinos exiliados durante el Gobierno federal de Juan Manuel de Rosas; quien había defendido la soberanía del territorio manteniéndolo aislado del abusivo comercio inglés y francés. Alberdi tenía uno de los rasgos más comunes entre los exiliados y emigrados: el transferir prácticas sociales y culturas políticas a través de redes civiles internacionales ${ }^{18}$. La obra que inspiró a los constituyentes remarcaba que "no debe cerrarse el país a la acción civilizadora de Europa, ya que en América todo lo que no es europeo es bárbaro" y que "gobernar es poblar". Y así se propició constitucionalmente el aumento de la población a través de la inmigración europea y sus hábitos civilizados que educarían al pueblo ${ }^{19}$.

Inmediatamente se comenzó una rectificación de la orientación educativa dominante hasta el momento. Se dejó a un lado la educación de las disciplinas filosóficas y se las reemplazó por el conocimiento de las ciencias prácticas y aplicadas, que brindaran una utilidad inmediata. También, se desterró de los planes de estudio el latín y se obligó el aprendizaje del inglés, "idioma de la libertad, la industria y el orden". Pero todos estos cambios iniciales fracasaron, faltaban maestros y recursos, y el pueblo se mantuvo alejado de las escuelas e indiferente de todas las cuestiones relacionadas con la enseñanza ${ }^{20}$. No será hasta el regreso de un exiliado, que la provincia de Buenos Aires se convirtió en el centro renovador de la educación de la Republica entre 1856 y 1861.

Desde su llegada a Buenos Aires, Domingo F. Sarmiento ${ }^{21}$, desde el cargo de jefe del Departamento de Escuelas en el que fue designado en junio de 1856, sintetizó todas las experiencias pedagógicas que había recolectado en sus viajes por Europa y Estados Unidos, y las implementó en su joven República; logró que la educación tuviera una renta propia, por ley sancionada en 1857; se preocupó para que las escuelas tuvieran edificios adecuados y exclusivos para la educación, dotando a la ciudad de Buenos Aires de dos escuelas monumentales, conocidas como la Catedral al Norte y Monserrat, y casas para escuelas en poblaciones bonaerenses. Era necesario mejorar el magisterio y formar una opinión publica favorable hacia la educación. Por tal motivo fundó la primera publicación pedagógica del país denominada Anales de la Educación Común. También, por la falta de preceptores en las escuelas más alejadas del interior de la provincia, se proyectó la fundación de dos

\footnotetext{
${ }^{18}$ Mollés, "Exiliados, emigrados y modernizadores: el crisol masónico euro-argentino (Europa-Rio de la Plata, 1840-1880)", en La masonería española en la época de Sagasta, coord. José Aantonio Ferrer Benimeli (Zaragoza: CEHME, 2006), Tomo I, 48.

${ }^{19}$ Manuel Solari, Historia de la Educación Argentina (Buenos Aires: Paidos, 1987), 113-114.

${ }^{20}$ Solari, Historia de la Educación Argentina, 116.

${ }^{21}$ Nace en 1811 en la provincia de San Juan y fallece en Paraguay en 1888, habiendo llegado a ser general del ejército, diputado y senador nacional, embajador en los Estados Unidos, gobernador de San Juan y presidente de la Republica. Iniciado masón en su exilio en Chile, en la logia Unión Fraternal de Valparaíso en 1854, a su vuelta a Buenos Aires se incorporará a la logia Unión del Plata no. 1. En 1860 se le otorgará el grado 33 del rito escocés antiguo y aceptado junto al presidente de la Republica y al gobernador de Buenos Aires. Finalmente, luego de estar separado de la institución durante años, se reincorporará para ser elegido gran maestre y soberano comendador en el año 1882.
} 
escuelas normales, una de maestros y otra de maestras, para solucionar el problema de la formación del magisterio.

Todo esto llevó a que la educación pública en la provincia de Buenos Aires fuera la más adelantada en Sudamérica, en tan solo seis años. Y llegará a su cúspide cuando Sarmiento fue elegido presidente de la Nación en 1868. Desde el Poder Ejecutivo impulsó de forma extraordinaria la instrucción primaria, orientó la secundaria y elevó el magisterio a "un importante agente civilizador". Por decreto de junio de 1870 fundó la escuela normal de Paraná, con el fin de formar maestros competentes, capaces de cumplir su misión. La escuela sería la cuna del magisterio argentino y como tal requirió de educadores con los conocimientos necesarios para que comenzara a funcionar. No habiéndolos en el país se contrató a norteamericanos como Jorge A. Stearns y su mujer, y a españoles como José María Torres y Enrique M. de Santa Olalla ${ }^{22}$, este último con gran prestigio en Chile ${ }^{23}$.

La influencia extranjera en la educación, traída por los gobernantes o por los propios educadores foráneos, ayudó a brindar soluciones pedagógicas que se adoptaron buscando aprovechar los resultados que habían logrado en sus países originarios. Esta tendencia a buscar en la pedagogía extranjera inspiraciones que servían para mejorar la educación es tan antigua como la Nación misma ${ }^{24}$. La influencia más permanente y decisiva fue la de la pedagogía francesa. De Francia se recibió el modelo de escuela normal nacional-estatal, el concepto de la formación del ciudadano, el principio de la limitación del Estado en las ideas y el principio de la democratización de la enseñanza. Por el contrario, de la pedagogía anglosajona se recibió el contenido prestalozziano ${ }^{25}$, introducido por los educadores norteamericanos y el libro La Educación del filósofo evolucionista Spencer, que hacia fines del siglo XIX se convirtió en la fuente doctrinaria de la mayoría de los educadores.

Y así llegamos a la década del ochenta, momento de fundación de la ciudad de La Plata y período de gran influencia del positivismo en la enseñanza argentina. Gracias al profesor de origen italiano Pedro Scalabrini se introdujo en la escuela de maestros el positivismo comptiano, mezclado con principios darwinistas y evolucionistas que, hacia fines de siglo, con la difusión de la psicología experimental y la sociología, se asoció al

\footnotetext{
${ }^{22}$ Boletín de Procedimientos del Soberano Gran Consejo General Ibérico y la Gran Logia Simbólica Española -en adelante BP-GCGI-GLSE-14,"Nuestros Grabados" (1893): 6-9.

${ }^{23}$ Habiendo nacido en Málaga en 1829, vivirá en Francia, Inglaterra, Cuba, Estados Unidos, Ecuador y Chile, para establecerse definitivamente en Argentina en el año 1865. Especialista en la fundación de escuelas para maestros, fue un reconocido educador de instrucción primaria, publicista, escritor y librepensador. En la provincia de Buenos Aires desempeñó el cargo de inspector general de escuelas hasta su jubilación en 1887. Llegará a la ciudad de La Plata en 1884, cuando los Poderes públicos se trasladaron a la ciudad. Habiendo sido iniciado en la Logia Libertad no. 48 de San José de Flores, se incorporó a la Logia La Plata no. 80 en 1887, para luego ser el ideólogo y máximo impulsor de la fundación de la Gran Logia Provincial Bonaerense. Finalmente fallese en La Plata en el año 1909.

${ }^{24}$ Solari, Historia de la Educación Argentina, 158-159.

${ }^{25}$ Johann H. Prestalozzi (1746-1827), educador de origen suizo que aplicó los ideales de la ilustración a la pedagogía.
} 
movimiento pedagógico científico. Y ambas corrientes determinaron durante décadas la orientación pedagógica nacional. Scalabrini fue designado profesor de filosofía y ciencias naturales en la escuela normal de Paraná, donde introdujo las doctrinas positivistas de Comte, Spencer y Darwin, junto a sus propias observaciones, que se encargó de difundir a todo el país a través de su publicación La Escuela Positiva.

A inicios de la década más progresista que tuvo la Republica en el siglo decimonónico, por decreto del Poder Ejecutivo de diciembre de 1881, se convocó un congreso pedagógico de profesores y personas competentes para tratar "las cuestiones relativas a la enseñanza y la educación popular con el objeto de impulsarla y mejorarla"26. Inaugurado en abril de 1882, al congreso pedagógico sudamericano asistieron las personalidades de la política y la educación más relevantes de la región. A lo largo del mes que disertaron las distintas comisiones y una vez finalizado el debate de los puntos del programa, se formularon conclusiones sobre la gratuidad y gradualidad de la enseñanza, la educación de la mujer, los programas escolares, los métodos de enseñanza, etcétera. Y estas fueron tomadas en cuenta por los legisladores que en 1884 sancionaron la ley 1.420 de Educación.

La ley de educación de 1884, es fruto de los años de lucha de hombres como Domingo F. Sarmiento, que además de recoger las conclusiones del congreso pedagógico, se inspira en parte por la ley de educación de la provincia de Buenos Aires del año 1875, influida por la pedagogía norteamericana importada por Sarmiento. Por otro lado, se inspira en la ley francesa de 1882 que surgió del movimiento democrático y liberal que intentó retornar a la política educativa de Nicolás de Condorcet y la revolución. Cuatros principios fundamentales le sirven de base para la organización de las escuelas primarias desde hace ya más de 133 años: La obligatoriedad de la educación primaria le es impuesta a los padres y tutores de los niños en edad escolar, pero no obliga a la concurrencia de estos a la escuela, pudiendo asistir a "establecimientos privados" o en el hogar del niño. La gratuidad, consecuencia del principio anterior, la pone al alcance de todos. La gradualidad impone una educación progresiva de los contenidos educativos. Y la neutralidad en materia religiosa, que fue una solución intermedia entre las dos tendencias contrapuestas que existían. La ley no estableció la escuela laica, sino que colocó al Estado en una posición neutral ante las distintas creencias ${ }^{27}$. No se impide la enseñanza religiosa, pero la limita a los niños que ya tienen una religión determinada, poniéndola a cargo de los ministros autorizados de los cultos y no involucrando al cuerpo docente. Además, establece que la enseñanza religiosa debe ser dada fuera de las horas de clase; por consiguiente, no es considerada una asignatura ordinaria de la enseñanza.

\footnotetext{
${ }^{26}$ Juan Carlos Vedoya, Historia de la Instrucción Primaria en la República Argentina (Tandil: Universidad Nacional del Centro de la Provincia de Buenos Aires, 1984), 119.

${ }^{27}$ Art. 2 de la Constitución de la Nacional Argentina: "El Gobierno Federal sostiene el culto católico apostólico romano".
} 
La provincia de Buenos Aires que había estado siembre en la cúspide de la civilización, había quedado rezagada después de la entrega del municipio de Buenos Aires para ser la Capital Federal, ya que en este acto se entregó la vieja Universidad de Buenos Aires. No puede dejar de mencionarse como un evento relevante en la enseñanza argentina del siglo XIX, la presentación en la Legislatura bonaerense de un proyecto para crear una universidad bonaerense, en 1889, por parte de cuatro senadores masones: Valentín Fernández Blanco, gran maestre del Gran Oriente de la Republica; Marcelino O. Aravena, miembro de la logia La Plata no. 80; Rafael Hernández, hoy considerado el padre de la institución universitaria; y Emilio J. Carranza ${ }^{28}$. El proyecto fue aprobado por unanimidad, creándose la Universidad Provincial de La Plata, la tercera del país. Sin embargo, su instalación oficial no será hasta $1897^{29}$.

\section{Productos de la pedagogía experimental}

Inspirados por la nueva legislación argentina en materia de educación y por las novedosas doctrinas positivistas de moda en los círculos intelectuales, las experiencias alternativas y de educación no estatal tendrán una fuerte presencia en la ciudad de La Plata. Entre ellas encontramos el Liceo de La Plata para señoritas, dirigido por la librepensadora Carolina Casas de Santa Olalla ${ }^{30}$; la Escuela del Pueblo para niños y adultos fundada por un matrimonio de maestros del Centro Socialista ${ }^{31}$; y la Escuela Colmena presidida por la dirigente feminista local Camila Burgos Meyer orientada hacia la formación de niños y adultos, en especial entre la colectividad rusa que comenzaba a afincarse en los suburbios de la capital como mano de obra barata de los frigoríficos ${ }^{32}$.

En la era considerada de progreso indefinido, La Plata parecía ser el lugar ideal para experimentos educativos y formas de enfrentar los problemas sociales desde una perspectiva distinta. Los sectores más avanzados de la elite intelectual platense promovieron numerosos emprendimientos donde convergían la pequeña burguesía universitaria y magistral con una clase obrera de rasgos distintos a los de Buenos Aires ${ }^{33}$. Los fundadores de la nueva institución masónica bonaerense eran parte de esta elite de intelectuales emprendedores, que proponiéndose trabajar en el seno de la clase obrera, diseñaron un sistema pedagógico nuevo partiendo de la sintetización de un novedoso rito masónico de corte racionalista.

\footnotetext{
${ }^{28}$ El Día, “Cámara de Senadores", 13 de julio de 1889, 1.

${ }^{29}$ AHPBA. La Plata. Ministerio de Gobierno. Año 1897. Leg. 4 Exp. 342/0.

${ }^{30}$ La Capital, "Liceo de La Plata", 16 de marzo de 1888, 1.

${ }^{31}$ La Vanguardia, “Almanaque del Trabajo”, enero 1920, 225.

${ }^{32}$ Dora Barrancos, Educación, cultura y trabajadores (1890-1930) (Buenos Aires: Centro Editor de América Latina, 1991), 51.

${ }^{33}$ Daniel Omar De Lucia, "La tradición laica en la ciudad universitaria: El movimiento librepensador en La Plata (1896-1919)", en La Universidad de La Plata y el Movimiento Estudiantil: Desde sus origenes hasta 1930 (La Plata: Edulp, 1999), 14.
} 
El flamante rito fue denominado por estos masones como rito científico ecléctico y obedecía a dos grandes necesidades. La modernización de los rituales era una de las demandas que exigían los masones, como expresión racional y positivista de las practicas masónicas $^{34}$. Con él se abandonaban las jerarquías, usos y costumbres de la masonería europea, que recordaban a las prácticas del clero. "Justificándose los altos grados sin que puedan ser prostituidos por los que no los merezcan, ni adjudicarlos por favoritismo, intrigas o procedimientos ruines ${ }^{\$ 35}$. Por lo tanto, la primera motivación de su creación fue ideológica; para rivalizar con el extendido rito escocés antiguo y aceptado, que ellos describían como un rito que "lleva en su esencia las formas del catolicismo y de la aristocracia, con su modo particular de ser" ${ }^{36}$. La segunda motivación obedecía a la tendencia pedagógica positivista predominante, donde la instrucción educativa se limitaba a conocimientos objetivos de aplicación práctica, eliminándose de los planes de estudio todo lo inútil ${ }^{37}$. Por tal motivo el nuevo rito era publicitado como "el más liberal y menos plagado de ceremonias inútiles, de todos los ritos conocidos" ${ }^{\$ 8}$ considerando a la masonería una ciencia positiva.

Lo que distinguía al simbolismo masónico ecléctico de la Gran Logia del resto, era el estudio elemental de la geometría. Ya que reemplazaba el simbolismo de las herramientas de trabajo propios de la francmasonería, como elementos alegóricos morales, por las propiedades de las figuras matemáticas "estudiando las nociones generales de figurabilidad, en el orden que establece la sucesión de cada figura geométrica que caracteriza a cada respectivo grado"39. Es de destacar que la idea de piedra bruta de la masonería tradicional era reemplazada por la idea de "triangulo irregular" y la idea de piedra cubica, por la de "triangulo perfecto".

\footnotetext{
${ }^{34}$ María Elena Rodríguez Lettieri, “La masonería española en la República Argentina (1890-1930)”, en La masonería española en la época de Sagasta, coord. errer Benimeli (Zaragoza: CEHME, 2006), Tomo I, 754.

${ }^{35}$ BP-GCGI-GLSE 8, "Primer aniversario de la Logia Madre Villarino" (1895): 13.

${ }^{36}$ BP-GCGI-GLSE 7, “¿Qué es la Masonería?” (1894): 2.

${ }^{37}$ Solari, Historia de la Educación Argentina, 185.

${ }^{38}$ Enrique Santa Olalla, El Instructor del Rito Ecléctico (La Plata: GLRB, 1894), portada.

${ }^{39}$ Santa Olalla, El Instructor del Rito Ecléctico, 24.
} 


\begin{tabular}{|c|c|}
\hline \multicolumn{2}{|c|}{ Masonería científico-ecléctica } \\
\hline \multirow{2}{*}{$1^{\circ}$ Grado Ecléctico Grado } & Triangulo Irregular \\
\cline { 2 - 2 } & Triangulo Isósceles \\
\cline { 2 - 2 } & Triangulo Perfecto \\
\hline $\begin{array}{c}2^{\circ} \text { Grado Ecléctico } \\
\text { Grado del } \\
\text { Cuadrilátero Ecléctico }\end{array}$ & Rombléctico \\
\cline { 2 - 2 } & Cuadrilátero Irregular \\
\hline \multirow{2}{*}{$\begin{array}{c}3^{\circ} \text { Grado Ecléctico } \\
\text { Grado del } \\
\text { Polígono Ecléctico }\end{array}$} & Polígono Irregular \\
\cline { 2 - 2 } & Icoságono Perfecto \\
\hline $\begin{array}{c}\text { Dr. en Ciencia Masónica } \\
\text { Grado del Orden de la } \\
\text { Sabiduría }\end{array}$ & Circulo \\
\hline
\end{tabular}

Grados científico-eclécticos y las figuras geométricas estudiadas.

\section{Una corporación masónica de vanguardia}

Vale notar que La Plata había estado lo suficientemente alejada de la capital federal como para contar con puerto propio, pero demasiado cerca como para incluir en su plan fundacional una universidad. Pocos años antes de instalarse la Universidad Provincial de La Plata en 1897, salvando las diferencias, otra institución platense fue pionera en establecerse en la ciudad atribuyéndose el lugar de "Alta Casa de estudios", instruyendo a los ciudadanos bajo un vanguardista proyecto educativo y con una estructura académica solo comparable con una facultad universitaria. La Gran Logia Provincial Bonaerense vino a aliviar la necesidad de formación especial y superior que existía en una parte de la pequeña burguesía masónica de la capital ${ }^{40}$, ante la imposibilidad de acceder a los grados superiores del rito escocés antiguo y aceptado, arbitrariamente administrados desde la capital, y ante la paralización del proyecto universitario platense, por el contexto económico desfavorable. Las obras de la ciudad, el mayor emprendimiento edilicio de la época, sufrieron las

\footnotetext{
${ }^{40}$ Se destaca que el masón Marcelino O. Aravena, uno de los senadores que en 1889 había impulsado en la Legislatura el proyecto de universidad bonaerense, en el año 1892 presentó al Poder Ejecutivo provincial un proyecto para establecer en la ciudad un instituto provincial "a la altura de los de Europa y América", establecimiento que albergaría en su seno cuatro niveles educativos, la enseñanza primaria o elemental, la enseñanza preparatoria o secundaria, la enseñanza comercial, y la enseñanza especial. El proyecto nunca fue aprobado, sin embargo, demuestra la obstinación de algunos masones en instalar una educación de excelencia en la ciudad. Extraído de AHPBA. La Plata. Ministerio de Gobierno. Año 1894. Leg. 7 Exp. 635/0.
} 
consecuencias de la debacle económica de la crisis argentina de 1890 a solo ocho años de la fundación; entre otras muchas iniciativas la puesta en marcha de la ya creada universidad quedará suspendida ${ }^{41}$ a pesar del reclamo de los vecinos ${ }^{42}$.

Surgida en medio de la crisis económica conocida como "Pánico de 1890", la Confederación de Logias Unidas de La Plata que por el año 1891 reunía a siete logias independientes, funda ese mismo año la Gran Logia Provincial Bonaerense, manifestando entre sus razones "la notable decadencia de la masonería argentina por la salida de los hermanos más distinguidos por su ilustración" "43. Contando entre los cargos administrativos de la asociación con distinguidos hombres de la diplomacia y la educación, fue elegido como primer gran maestre el diplomático y juez platense Dámaso E. Uribúru, quien pocos meses antes junto a otros vecinos, había dirigido al gobernador una nota reclamando la apertura definitiva de la Universidad Provincial ${ }^{44}$.

Un relevante papel tuvo el masón y pedagogo de origen español Enrique M. de Santa Olalla, conocido en la región por sus proyectos pedagógicos filantrópicos, quien una vez retirado de la función pública se embarcó en un nuevo emprendimiento educativo insólito para la época. Santa Olalla fue el responsable de sintetizar el nuevo rito racionalista basado en la enseñanza de la geometría y estructurado en tres grados ${ }^{45}$ que presentaba a la masonería como una ciencia. En las logias del rito científico ecléctico los ascensos se otorgaban únicamente siendo aprobados en examen, que podían pedir los interesados, cuando se consideraban aptos. En contraposición al Supremo Consejo del Rito Escocés Antiguo y Aceptado del Grado 33, cuyos ascensos eran a través de manejos fraudulentos en los procesos electorales ${ }^{46}$ y la compra de voluntades, otorgando altos grados, con la sola intención de mantener el statu quo en la jurisdicción ${ }^{47}$.

En la institución de vanguardia se seguía el sistema filosófico indicado por el médico cubano Vicente Antonio de Castro Bermúdez ${ }^{48}$, autor del libro Educación Elemental Masónica, donde se propone que la Francmasonería tiene que estar conformada

\footnotetext{
${ }^{41}$ Fernando Gandolfi, "Pretérito Imperfecto: Los días de la primera universidad de La Plata (1890/97-1905)", en La Universidad de La Plata y el Movimiento Estudiantil: Desde sus orígenes hasta 1930 (La Plata: Edulp, 1999), 42.

${ }^{42}$ Entre las solicitudes que se conservan reclamando la apertura de la universidad, se destaca en el año 1894 la presencia de Manuel Riafrecha, empleado de la Dirección General de Escuelas e importante miembro de la Gran Logia Bonaerense. Extraído de AHPBA. La Plata. Ministerio de Gobierno. Año 1897 Leg. 3 Exp. 202/0.

${ }^{43}$ Boletín Oficial de la Confederación de Lojias Unidas 9-10, "Razón de ser de la Gran Logia Provincial Bonaerense" (1891): 61.

${ }^{44}$ AHPBA. La Plata. Ministerio de Gobierno. Año 1893. Leg. 8 Exp. 749/0.

${ }^{45}$ Según la bibliografía de la Gran Logia, el rito empleado era el del barón de Kanigge que había sido inventado en Alemania en 1793, amalgamado con las doctrinas en materia pedagógica de Enrique de Santa Olalla.

${ }^{46}$ Rodríguez Lettieri, “La masonería española en la República Argentina (1890-1930)”, 754.

${ }^{47}$ Revista Masónica 8 "La convención masónica y la reforma de la Constitución” (1894): 117-118.

${ }^{48}$ Con el nombre simbólico de Viriato Alfonso de Covadonga, fue uno de los fundadores en 1861 del Gran Oriente de Cuba y las Antillas.
} 
por una enseñanza dividida en preparatoria, elemental y superior. Por primera vez se emulaban las distintas etapas de la enseñanza pública argentina, bajo una institución masónica.

(...) Nosotros no hacemos ostentación de repartir dinero en abundancia, ni de dar banquetes, porque nuestro rito profesa el estoicismo y no permite gastar dinero a lo Lúculo pudiéndole dar mejor destino. En cambio, damos instrucción y vemos con placer que ésta se aprovecha, llenando así uno de los fines de la masonería moderna $^{49}$.

Por otra parte, la institución también estuvo a la vanguardia en lo referido a la difusión de instrucción masónica a través de la prensa especializada. En concordancia con las publicaciones pedagógicas argentinas, populares en los círculos educativos, el Boletín Oficial de la Gran Logia Bonaerense era descripto por sus pares como una publicación científica de instrucción masónica, esencial para el rito científico ecléctico ${ }^{50}$ el cual era difundido a todas las logias de la asociación y a distintas redacciones nacionales como de América $^{51}$ y Europa $^{52}$.

\section{El Gran Oriente Ibérico en Argentina}

Tan solo tres meses después de su fundación en La Plata, en febrero de 1892 el Gran Consejo General Ibérico y su Gran Logia Simbólica Española reconocen y establecen relaciones formales con la corporación bonaerense, entablando ambas garantes de amistad para redactar un pacto ${ }^{53}$, que no se materializará hasta el año siguiente. Con el acuerdo de patronato firmado, se estableció que la institución española patrocine a la argentina, convirtiéndose esta última en Honorable Gran Logia Regional Bonaerense, extendiendo su jurisdicción a toda Sudamérica y representando al rito oriental de Memphis y Mizraim en territorio americano ${ }^{54}$. Merece un párrafo aparte el origen en 1887 de la institución española que patrocinó a la Gran Logia Bonaerense, para vislumbrar los cambios estructurales que sufrirá la primera durante el año 1895.

Al igual que la asociación platense, su fundación fue llevada a cabo por un grupo de masones que pertenecían a la alta, media y pequeña burguesía ${ }^{55}$, el mismo año de la promulgación por el gobierno liberal de Sagasta de la Ley de Asociaciones que legalizó los

\footnotetext{
${ }^{49}$ Revista Masónica 6, "De La Plata" (1896): 91.

${ }^{50}$ Revista Masónica 8, "Boletín Oficial" (1894): 110.

${ }^{51}$ Boletim do Grande Oriente do Brazil 8, "Publicações Recebidas" (1890): 207.

${ }^{52}$ Cádiz Masónico 6, "Publicaciones" (1890): 6.

${ }^{53}$ BP-GCGI-GLSE 10, "Soberana Gran Logia Simbólica Española” (1892): 3-4.

${ }^{54}$ BP-GCGI-GLSE 12, "Sección Oficial” (1893): 14.

${ }^{55}$ Eduardo Enríquez del Árbol, "Al filo de un centenario: El último Gran Oriente Hispano del siglo XIX: La Gran Logia Simbólica Española del Rito Primitivo y Oriental de Memphis y Mizraim (1889-1989)”, en Masonería, Revolución y Reacción, coord. Ferrer Benimeli (Zaragoza: CEHME, 1990), Tomo II, 998-1000.
} 
partidos políticos, las asociaciones obreras y permitió la adscripción legal de la masonería y algunas corporaciones religiosas ${ }^{56}$.

La Gran Logia europea administraba los grados originales de la masonería simbólica a través de grandes logias provinciales y el Gran Consejo Ibérico administraba los grados superiores de la masonería filosófica ${ }^{57}$, llegando a estar constituido por un número indefinido de miembros o consejeros honoríficos, dieciocho consejeros supernumerarios, quince consejeros numerarios, asumiendo los últimos la dirección, gobierno y administración del rito, así como sus relaciones interiores y exteriores. Tenía bajo sus auspicios y obediencia todos sus cuerpos superiores y auxiliares, un capítulo general del real arco, diez capítulos consistoriales y ocho grandes cámaras areopágicas ${ }^{58}$.

Eligiendo un rito masónico alternativo al escocés ${ }^{59}$, se convirtieron en los únicos representantes del "orientalismo" en España, al reformar y adoptar el rito de MemphisMizraim del Imperial Supremo Consejo General de Nápoles ${ }^{60}$. Su elección, por parte de los masones fundadores, resultó de la búsqueda del rito masónico más antiguo después de la fundación de la Gran Logia de Inglaterra en 1717, encontrando el rito de inspiración egipcia de Memphis-Mizraim de 96 y 90 grados respectivamente, que al parecer había sido creado en Nápoles en el año 1747, y como su nombre lo indica, representaba el doble país de Egipto unificado desde la primera dinastía.

La reforma ritualística efectuada, fue llevada a cabo por Isidro Villarino del Villar, futuro gran maestre de la institución, que separó los grados simbólicos de los capitulares y filosóficos, conformando lo que se conoció como antiguo y primitivo rito oriental de Memphis y Mizraim reformado, además de concederle dentro de la masonería iguales derechos a la mujer que al hombre ${ }^{61}$. La reforma obedeció a la necesidad de buscar un remedio a la problemática de la clase obrera española, por parte de esta asociación masónica, considerada la más "politizada" de todas ${ }^{62}$, incorporando a las mujeres como asociadas y adaptando los grados simbólicos y filosóficos a la realidad española; con un alto analfabetismo, extrema pobreza en los municipios encargados de asegurar la enseñanza primaria y libros de pedagogía escasos, malos y caros.

\footnotetext{
${ }^{56}$ Enríquez del Árbol, "El mundo obrero de la prensa masónica: El $1^{\circ}$ de mayo de 1890 en el Boletín de Procedimientos del Gran Oriente Ibérico", REHMLAC+ 8, no. 1 (Mayo-Noviembre 2016): 91-92, citado el 12 de marzo de 2017, doi: http://dx.doi.org/10.15517/rehmlac.v8i1

${ }^{57}$ Pedro Álvarez Lázaro, "Pluralismo masónico en España”, en La Masonería en la España del siglo XIX, coordFerrer Benimeli (Zaragoza: CEHME, 1987), Tomo I, 38.

${ }^{58}$ BP-GCGI-GLSE 1-2, "Rito Nacional Español" (1897): 3.

${ }^{59}$ Hacia fines del siglo XIX, en España llegaron a coexistir ocho instituciones masónicas diferentes que practicaban el rito escocés antiguo y aceptado.

${ }^{60}$ Enríquez del Árbol, "La Injusticia social en la prensa masónica de fines del siglo XIX: El Boletín de Procedimientos del Gran Oriente Ibérico", REHMLAC+ 7 no. 1 (Mayo-Noviembre 2015 [citado el 12 de marzo de 2017]): disponible en http://revistas.ucr.ac.cr/index.php/rehmlac/article/view/19945/20101

${ }^{61}$ BP-GCGI-GLSE 2, "Villarino en América" (1893): 2.

${ }^{62}$ Enríquez del Árbol, El mundo obrero de la prensa masónica”, 93.
} 


\section{La formación de los maestros}

La historia de las instituciones dedicadas a la formación de los maestros corrió pareja con la del desarrollo y organización de los sistemas nacionales de educación, con el proceso de institucionalización del aparato escolar en el ámbito de la educación elemental $^{63}$. Como hemos visto, en el caso argentino, la fundación de escuelas normales para la formación de maestros había sido la base de la educación argentina desde mediados de siglo; debiendo su nombre al objetivo inicial de estas instituciones de establecer las normas de enseñanza para los estudiantes de pedagogía.

En lo que respecta a la institución masónica bonaerense, cabe destacar la existencia de un cuerpo administrativo asociado, denominado Soberana Gran Logia Federal de Maestros. Su creación data del año 1891 y se encontraba ubicada en un local del barrio platense de Tolosa frente a los talleres del Ferrocarril Oeste, enclave de la clase obrera de la capital. A pesar de titularse "Soberana y Federal", se trataba de un taller masónico compuesto únicamente por asociados con el rango de maestro masón, que tenía bajo su dirección la formación de todas las logias de la institución. En ella se generaban los planes de estudios y los cuestionarios de examen que el Poder Legislativo debía aprobar, además se instruían a los maestros en los grados intermedios del rito científico ecléctico y del antiguo y primitivo rito oriental de Memphis y Mizraim.

De su plan formativo se ha podido saber que poseía una escuela técnica para masones y otra similar para ciudadanos ajenos a la institución, donde se impartían matemáticas industriales, en dos cursos de forma gratuita para aquellos que se inscribiesen ${ }^{64}$. El alto grado de instrucción científica impartido se comprueba a través de las crónicas de la época: En ocasión del solsticio de invierno de 1894 se desarrolló una conferencia pública en este cuerpo ante vecinos platenses, en la cual se demostró en una pizarra la relación de la eclíptica terrestre con el zodíaco, pudiendo comprobarse matemáticamente cómo se producen los equinoccios y los solsticios ${ }^{65}$.

La creación de "grandes logias temáticas" orientadas a satisfacer ciertas necesidades o con el fin de reunir a determinados colectivos de asociados no es original de esta institución. La Gran Logia de Instrucción, la Gran Logia Militar y la Gran Logia de Adopción de la Clase Obrera adscriptas a la Gran Logia Simbólica Española son un claro ejemplo. A través de estos cuerpos la asociación europea se colocó en una posición de apertura y comprensión como no lo había hecho hasta entonces ningún cuerpo masónico español, siendo uno de los rasgos que caracterizará la fisonomía particular de la Gran Logia

\footnotetext{
${ }^{63}$ Agustín Escolano Benito, "Las Escuelas Normales, siglo y medio de perspectivas históricas", Revista de ciencias de la educación: Órgano del Instituto Calasanz de Ciencias de la Educación 157 (1994): 55.

${ }^{64}$ Revista Masónica 6, "De La Plata" (1896): 91.

${ }^{65}$ Revista Masónica 15, "Fiesta de Solsticio de Invierno" (1894): 202-203.
} 
Española $^{66}$, solo comparable a la preocupación que demostraba, en el otro extremo del Atlántico, la institución bonaerense por la educación de sus afiliados.

La idea de crear una escuela de formación de maestros masones había sido de quien era el gran secretario de la institución Enrique de Santa Olalla, quien en 1857 había dirigido la Escuela Mercantil de Valparaíso de formación de profesores y en 1865 la Escuela Normal de preceptores de Buenos Aires; además de colaborar en la fundación de las escuelas normales de Paraná y La Plata. Este proyecto de instruir a los asociados con responsabilidades pedagógicas en los talleres había surgido ante la falta de voluntad y medios para la instrucción, por parte del Gran Oriente de la Republica, que según los masones disidentes se encontraba sumido en una crisis moral y formativa ${ }^{67}$.

\section{La educación preparatoria y elemental}

La nueva ley de educación, planteaba una escuela pública aconfesional y gratuita. Ante tal manifestación de progreso, los masones argentinos se posicionaron como "agentes civilizadores" con la responsabilidad de educar al pueblo ante el "supuesto avance del jesuitismo sobre la ciudadanía". En una ciudad como La Plata, símbolo de la ciencia positiva y la fe en el progreso indefinido, estas políticas educativas tomaron gran impulso y se manifestaron a través de proyectos filantrópicos donde la enseñanza técnica, la gratuidad y el laicismo eran sus bases programáticas.

Producto del flamante rito cientificista, se había diseñado un sistema masónico que requería un alto grado de exigencia intelectual, y esto era compensado con un período de preparación previo a la iniciación masónica, que se denominó Escuela Técnica Masónica, donde los futuros asociados eran instruidos en las artes y las ciencias básicas, al estilo de una escuela primaria o preparatoria. Se trataba de una escuela dominical que claramente estaba pensada para competir con la misa católica. Al parecer éste era un rasgo distintivo en la nueva capital de impronta laicista; generalmente las escuelas de oficios dirigidas por los masones locales elegían los domingos para sus reuniones, como lo hará el masón catalán Luis Ricardo Fors al frente de la Biblioteca Municipal, organizando lecturas dominicales, al estilo de sermones laicos en directa competencia con la misa dominical, en donde notables instruían al pueblo contra el retrógrado clero y a favor del libre examen ${ }^{68}$.

La escuela preparatoria no solo era obligatoria para los profanos que quisieran ingresar en la institución, también existía una escuela obligatoria para todos los aspirantes a ser elevados en los distintos grados eclécticos, ya que el taller que lo suprimiera era

\footnotetext{
${ }^{66}$ Enríquez del Árbol, Al filo de un centenario, 1000.

${ }^{67}$ Boletín Oficial de la Confederación de Lojias Unidas 9-10, "Razón de ser de la Gran Logia Provincial Bonaerense" (1891): 62.

${ }^{68}$ Alicia Vidaurreta, "Luis Ricardo Fors Librepensador y Bibliógrafo", en Redescubriendo un continente: La inteligencia española en el París Americano en las postrimerías del siglo XIX, comp. Hugo Biagini (Sevilla: Diputación Provincial, 1993), 293.
} 
declarado irregular y sus trabajos nulos ${ }^{69}$. La escuela suplantaba al gabinete o cuarto de reflexión del rito escocés, por considerarlo tétrico e innecesario, y debía ser dirigida por los masones que ostentaran el oficio de orador y experto. A su vez, las escuelas técnicas, en las distintas localidades donde estaban emplazadas, prestaban el servicio gratuito de formar a la clase obrera bonaerense, impartiendo cursos de dibujo técnico y matemáticas industriales ${ }^{70}$.

Aunque las principales asignaturas que se cursaban eran la geometría, el dibujo, la aritmética y la trigonometría, también se estudiaba moral, a través de los autores Smith, D’Holbach y Spencer; filosofía, a través de Comte, Strauss, Schopenhauer y Laromiguiére; además de física, historia y legislación. Mientras que las preguntas de los distintos exámenes debían ser contestadas a través del estudio de las religiones, leyendo a autores como Voltaire, Le Brun, Renan, Julio Simón; y de libros como Las Ruinas de Palmira de Volney, El Origen de los Cultos de Dupuy, El Citador de Pigault Lebrun, La Religión Natural de Jean Meslier, El Tratado de los Tres Impostores de autor desconocido y La Historia de las Religiones del masón franco-argentino Alejo Peyret.

De un análisis superficial del material utilizado encontramos a autores del materialismo, del panteísmo y del socialismo, así como algunos de los primeros sociólogos he historiadores de las religiones, quienes iniciaron el estudio científico del cristianismo, lo cual hizo de ellos y sus obras un terreno de batalla entre el clericalismo y el librepensamiento internacional. Todo esto era condensado en los planes formativos oficiales de instrucción para los distintos grados y en los cuestionarios de exámenes para superar las pruebas orales de los talleres. En esta etapa elemental de la educación de los masones se otorgaban los tres grados del rito científico, el grado del triángulo ecléctico, del cuadrilátero ecléctico y del polígono ecléctico.

Pero quizás, el detalle más evidente de que las logias de la asociación emulaban a los establecimientos educativos preparatorios o elementales, era que los asientos estaban colocados en línea paralela como si fuera un colegio, enfrentados a la mesa del presidente, a diferencia de la distribución habitual de las logias masónicas. La existencia de un reloj sobre una de las paredes, el ritual alternativo en casos de impuntualidad de los asociados y la insistencia en lo referido al tiempo de comienzo de las reuniones, recuerdan a los hábitos que la escuela primaria intenta enseñar desde temprana edad en el alumnado.

\section{La educación superior, una Alta Casa de estudios}

Si al finalizar la educación elemental, en la que se otorgaba el grado del polígono ecléctico, adquiriendo el asociado la categoría de maestro masón, se decidía continuar los estudios, se ingresaba en la Facultad Científica Masónica, colegio que impartía la

\footnotetext{
${ }^{69}$ Santa Olalla, El Instructor del Rito Ecléctico, 26.

${ }^{70}$ Revista Masónica 6, “De La Plata” (1896): 91.
} 
educación superior de la institución. Allí el estudiante podía acceder a los manuales de instrucción de Jean-Marie Ragon, Albert Pike, Vicente Antonio de Castro Bermúdez, Arcipreste Doménico Anghera, Eduardo Caballero de Puga y Luis Ricardo Fors, para formarse.

En el último de los exámenes de esta Facultad o Colegio Superior, el asociado se acreditaba como past-master ecléctico y recibía el último título simbólico, que, según el programa oficial, correspondía a la figura geométrica del "círculo" cuya figura era considerada la más perfecta. El título obtenido era el de doctor en ciencia masónica, que era el grado más alto e importante de la masonería ecléctica por los conocimientos científicos que se exigían para obtenerlo; pudiendo equipararse al grado 33 del rito escocés.

El último título simbólico daba derecho a entrar en el Supremo Consejo del Rito Ecléctico de La Plata con un cargo ad vitam. Este cuerpo superior estaba dirigido por un gran venerable e integrado por los directores del Supremo Consejo del Rito Ecléctico, todos ellos miembros past-masters grado 33. En el tiempo que existió fueron grandes venerables el inspector nacional de escuelas argentinas Pío Capdevila Maella, el gran maestre del Gran Oriente Ibérico Isidro Villarino del Villar, y el director del Colegio Francés Richelieu de La Plata Francisco Rodemet.

El Supremo Consejo platense había quedado constituido tres años después de la fundación de la asociación y a lo largo de la vida de la institución fue integrado por una veintena de masones de la provincia de Buenos Aires. Se destaca la presencia de una mujer como consejera honorifica; Margarita Práxedes Muñoz ${ }^{71}$. El gran maestro de la asociación bonaerense informaba su inauguración a la máxima autoridad del Gran Oriente Ibérico, de esta manera a fines de 1894:

(...) Tengo la satisfacción de poner en vuestro supremo conocimiento, que después de tres años de espera para instalar el Supremo Consejo Regional de Past-Masters Eclécticos Grado 33, no se ha podido conseguir su realización, hasta el día 10 del mes que expira, por falta de preparación de los hermanos, en la posesión de los conocimientos históricos, litúrgicos y científicos que se requieren, de acuerdo con los programas oficiales de la materia, para merecer el título legal de tan alta distinción, que es lo que da la importancia que lleva consigo la jerarquía del Grado $^{72}$.

\footnotetext{
${ }^{71}$ De origen peruano, fue filósofa, novelista y una de las primeras mujeres en estudiar medicina en Latinoamérica. En Argentina, se destacó por sus conferencias científicas y publicaciones feministas de librepensamiento, en las que participaban los intelectuales de la época.

${ }^{72}$ BP-GCGI-GLSE 2, "Soberano Gran Consejo General Ibérico" (1895): 4-5.
} 


\section{Repercusiones de sus políticas pedagógicas}

Como hemos comprobado, las redes civiles internacionales transferían prácticas sociales y culturas políticas en la región desde mediados de siglo XIX. Hacia fines de ese siglo Argentina ya era el principal foco de recepción y difusión de la modernidad occidental en Latinoamérica y un puente social y cultural entre América y Europa ${ }^{73}$. A través de asociaciones como la bonaerense se importaron doctrinas masónicas a la región sudamericana como el rito de Memphis y Mizraim, pero también culturas políticas, ya que sus asociados, en estrecha relación con los republicanos peninsulares, serán quienes funden el comité provincial del Partido Republicano Español y el Club Republicano Español de La Plata.

Estas redes masónicas atlánticas eran bidireccionales, no solo se importaba desde Europa, sino que también se exportaban hábitos y cultura masónica hacia Europa; el ya mencionado Boletín Oficial de la Gran Logia es un claro ejemplo de ello. Sin embargo, sus políticas pedagógicas hacia la clase obrera también serán transferidas a través de estas redes masónicas, logrando influir en la masonería española.

A través del Boletín Oficial del Gran Oriente Ibérico, el gran secretario Isidro Villarino afirmaba que en un país como España, donde había once millones de habitantes que no saben ni leer ni escribir, sería una quimera implementar un rito masónico como el científico ecléctico, que requería de hombres de profundos conocimientos ${ }^{74}$. Sin embargo, esta postura cambiará cuando la institución se verá obligada a modernizarse, para ser más efectiva en su misión con la clase obrera.

Debido a desacuerdos entre el Gran Consejo Ibérico y el Supremo Consejo General de Nápoles que lo patrocinaba, en enero de 1893 ambas se desvinculan y la asociación española decide adoptar una nueva identidad, aprovechando la independencia de la máxima autoridad del rito Giambattista Pessina con rasgos sacerdotales y jurisdicción mundial, propios de la masonería egipcia ${ }^{75}$. A partir de este momento procurarán diferenciarse del rito de Memphis-Mizraim de Nápoles y adquirirán una identidad más ibérica. En marzo de 1894, Isidro Villarino es electo máxima autoridad del Gran Consejo General Ibérico $^{76}$ e inmediatamente se firman acuerdos con la Federación de Logias Galaicas, asociación menor de talleres independientes de la región de Galicia, para integrarse a la Confederación del Gran Oriente Ibérico. Sin embargo, las condiciones eran marcadamente desventajosas para la asociación de Villarino, que pretendía reparar el debilitamiento institucional

\footnotetext{
${ }^{73}$ Mollés, "Un puente transatlántico: La Gran Logia Filial Hispano-Argentina del Grande Oriente Español”, en La circunstancia euro-americana de Entre-Guerras, coord. Ferrer Benimeli (Zaragoza: CEHME, 2007), Tomo I, 809.

${ }^{74}$ BP-GCGI-GLSE 20, "Villarino en América" (1893): 3.

${ }^{75}$ BP-GCGI-GLSE 2, "Aclaraciones Importantes" (1894): 2.

${ }^{76}$ Revista Masónica 14, "GCGI” (1894): 221.
} 
producto del alejamiento con Nápoles: Se daba total libertad a los talleres incorporados de administrar los tres primeros grados de la masonería simbólica del Rito Escocés, se eximía de pagar cualquier tipo de cuota o gravamen a las autoridades y afiliados con el Grado 33 que quisieran trabajar en el rito del Gran Oriente Ibérico, y se hacía especial hincapié en que "viviría en absoluta libertad e independencia, sin tener que tributar para nada al Gran Consejo General Ibérico"77.

Para mediados de 1894, se anuncia oficialmente que gracias a que la institución practicaba desde su fundación un rito reformado en España, se había logrado construir un rito con identidad propia. Esta identidad podía llamarse "orientalismo español" y sería la base $\mathrm{y}$ fundamento de un rito nacional nuevo, exclusivo del Gran Oriente Ibérico, denominado rito oriental ibérico ${ }^{78}$. Al mismo tiempo, el comunicado ordenaba abandonar los símbolos de la masonería egipcia y reemplazar el antiguo lema de los documentos oficiales por el lema "Al Progreso de la Humanidad - Rito Nacional Español"79. Sin embargo, el boletín oficial de la institución no menciona la reforma ritualística aprobada por el Gran Consejo Ibérico, que se estaba llevando a cabo; será el gran maestro de la Gran Logia Bonaerense quien, a través de sus escritos a lo largo de los meses en el boletín español, anoticie sobre el nuevo rumbo adoptado:

(...) Las logias no son ya templos para practicar exclusivamente ceremonias misteriosas, ineficaces la mayor parte, sin relación histórica que las justifique. Las logias son principalmente las escuelas del adulto, destinadas a dar instrucción complementaria en relación con los conocimientos sociales de cada individuo, donde el masón encuentre el sendero que lo conduzca a llenar su misión, como miembro de una sociedad progresiva, como patriota y buen ciudadano; donde adquiera la instrucción científica que todos los hombres necesitan para completar su saber. (...) Para conseguir la solución del problema social declarad en vuestros templos la Escuela Científica Obligatoria para los masones como lo tiene constituida el Rito Ecléctico Científico; levantad el nivel moral e intelectual de los grados simbólicos a la mayor altura posible de los grados filosóficos; que estos sean una verdad positiva, y no olvidéis que el masón debe cumplir del mejor modo posible la ley del perfeccionamiento humano ${ }^{80}$.

La asociación europea veía cómo sus esfuerzos no surtían efecto en la sociedad, y que los asociados percibían una decadencia institucional creciente. A tal efecto, emprenderá una reforma estructural de los órganos regionales, durante los primeros meses de 1895 , debido al fracaso de sus grandes logias regionales, y por consejo de Villarino, que ya era mencionado como el jefe supremo del rito nacional español. Además de suprimir estos

\footnotetext{
${ }^{77} B P-G C G I-G L S E$ 7, “Así se realiza la unión” (1894): 4-5.

${ }^{78}$ BP-GCGI-GLSE 12, "Soberano Gran Consejo General Ibérico” (1894): 10.

${ }^{79}$ CDMH. Salamanca. José Moser Giner. Leg. 17. Exp. 13.

${ }^{80}$ BP-GCGI-GLSE 7, "Conformes" (1895): 4-5.
} 
órganos regionales, se anulan los capítulos provinciales y los grandes areópagos regionales, incorporándolos a órganos administrativos mayores ${ }^{81}$, en un claro proceso de centralización. Al mismo tiempo se terminaba de estructurar el flamante rito nacional, que como demostraremos tuvo como principal fuente de inspiración el rito científico ecléctico de la Gran Logia Bonaerense.

En el discurso pronunciado en ocasión del primer aniversario de la logia Isidro Villarino de Buenos Aires durante el mes de abril, el gran maestro de La Plata anotició a los presentes sobre el nuevo rito español:

(...) Se acaba de crear en España el Rito Científico Español ${ }^{82}$ como continuación complementaria a la masonería fundamental o simbólica, por la alta potencia que nos patrocina, la cual se ha separado por completo del Rito de Mizraim, que antes profesaba. Al efecto se ha establecido en las logias ubicadas en las capitales de provincia de la península, la serie científica que sigue inmediatamente a la simbólica, siendo compuesta la anterior de tres grados universitarios, comprendiendo el Primer Grado Científico, las materias y la liturgia de los grados del 4 al 17 escocés. El Segundo Grado de esta nueva serie constituye el Bachillerato de la Ciencia Masónica, caracterizado en el grado 18 escocés y si éste continúa cursando las materias de los grados intermedios del 19 al 29 para obtener el Grado Tercero Científico que representa los Grandes Maestros con el título de Profesores de Ciencia Masónica, vinculado dicho grado en el 30 escocés. Por último (...) el grado más elevado de la institución que se titula Pas-Master Científico 33 que equivale al Doctorado en la Ciencia ${ }^{83}$ que funda sus misterios en el saber y en la práctica de todas las virtudes sociales ${ }^{84}$.

A la reforma antes mencionada, sobre los órganos regionales, la acompañó una reforma en los talleres de la Gran Logia Simbólica Española. Esta asociación hermanada al Consejo Ibérico daba gran importancia a la educación del individuo, sin embargo, la masonería española en general no sostenía escuelas propias como la asociación bonaerense, sino que se había dedicado a colaborar con grupos librepensadores y republicanos en la defensa y puesta en marcha de escuelas laicas y racionales ${ }^{85}$. Finalmente, el 30 de junio, el Gran Maestre Villarino decreta:

(...) De conformidad con lo propuesto, discutido y aprobado por la Gran Logia ante las iniciativas del ilustre y venerado hermano D. Enrique M. de Santa Olalla (...) a partir del $1^{\circ}$ de Julio de 1895 , es obligatorio en todas las Logias Simbólicas de

\footnotetext{
${ }^{81}$ BP-GCGI-GLSE 4, "Circular" (1895): 2-3.

${ }^{82}$ Se refiere al rito nacional español también conocido como rito oriental ibérico.

${ }^{83}$ El grado de doctor en ciencia masónica emulaba al grado más alto del rito científico ecléctico de la Gran Logia Bonaerense, y era equivalente al grado 33 del rito escocés antiguo y aceptado.

${ }^{84}$ BP-GCGI-GLSE 8, "Primer aniversario de la Logia Madre Villarino" (1895): 12-13.

${ }^{85}$ Enríquez del Árbol, "La Injusticia social en la prensa masónica de fines del siglo XIX”, 101.
} 
nuestra jurisdicción y obediencia, la constitución y sostenimiento de la Escuela Masónica Primaria. (...) Las Logias en que existen masones analfabetos o poco instruidos, se obligarán en el término de un año a enseñar a leer y escribir correctamente a cuantos pertenecen a cada una, si se hallaren faltos de instrucción, cuidando que dichos hermanos no se confundan con los de la escuela preparatoria de aspirantes profanos, que en lo sucesivo no podrán admitirse en la Orden sin rendir el correspondiente examen, sin molestar a los examinados con pruebas ridículas ni atentatorias a la dignidad humana, suprimiéndose el mal llamado gabinete de reflexiones. (...) De la más fiel y exacta realización de este nuevo y presente decreto, consideramos indefectiblemente la regeneración y engrandecimiento de la Orden ${ }^{86}$.

Como se ha demostrado, el rito nacional español, surgido del alejamiento del Supremo Consejo General de Nápoles y su rito de inspiración egipcia, fue estructurado según indicaba el proyecto pedagógico de la Gran Logia Bonaerense, con una enseñanza dividida en preparatoria, elemental y superior. Pero no solo esto; abandonó el deísmo egipcio y se refundó como un rito racionalista que planteaba a la Francmasonería como una ciencia positiva, elevando los conocimientos requeridos para practicarla. A tal efecto requirió de escuelas masónicas primarias para nivelar el conocimiento de los asociados, y de escuelas preparatorias para los aspirantes a masones, que en adelante deberían superar exámenes de admisión, como tenía la asociación argentina.

\section{Un final compartido}

La pretensión del gran maestre español, de regenerar la institución masónica, nunca pudo concretarse; pocos meses después de la modernización estructural y ritualística, comenzará la "crisis finisecular de la masonería española", período histórico de persecución y aislamiento de los masones españoles. Y al mismo tiempo, en Argentina se vivió una reacción conservadora contra determinados círculos de extranjeros, que dificultó el trabajo a las logias bajo patrocinio foráneo.

A mediados de 1896, las noticias de una revolución en la isla de Cuba habían provocado que los independentistas de Filipinas se sublevaran y formaran guerrillas contra las tropas españolas. El gobierno del país ibérico, influenciado por el clero no tardó en inculpar a la masonería que, en gran parte, estaba constituida por republicanos y anarquistas. Inmediatamente fueron encausados el gran maestre Pantoja y el gran secretario caballero de Puga de la institución masónica denominada Gran Oriente Nacional Español, y encerrados en la Cárcel Modelo de Madrid ${ }^{87}$. Se los acusaba de fomentar la propaganda

\footnotetext{
${ }^{86}$ BP-GCGI-GLSE 10, "Rito Nacional Español” (1895): 6.

${ }^{87}$ Revista Masónica 20, “España” (1896): 301.
} 
separatista a través de un miembro de la asociación, el independentista filipino Villaroel, presidente de la Logia Patria de la ciudad de Manila.

Aprovechando el clima de tensión entre determinadas elites y extranjeros, en Argentina se aumentó el hostigamiento a las logias bajo patrocinio extranjero, impulsado por el Supremo Consejo y Gran Oriente de la Republica con la intención de captar a los afiliados, entre ellas las del Oriente Ibérico.

En realidad, la oligarquía ganadero-industrial argentina en el poder había visto con espanto que en las incipientes asociaciones y círculos de inmigrantes se predicara la lucha contra los patrones y el Estado explotador ${ }^{88}$, y como reacción, de la mano de la Unión Industrial Argentina, llevó al Congreso de la Nación en 1899 un proyecto de ley buscando neutralizar y deportar a los extranjeros de la clase obrera organizada, que luego se materializó en la ley 4.144 de residencia. Salvando las distancias, lo mismo estaba ocurriendo en la institución masónica argentina desde algunos años antes, entre masones patricios y extranjeros. Producto de la misma reacción conservadora finisecular, determinados grupos de masones lograron reformar la constitución de la asociación masónica nacional para que se restrinja la instalación de logias extranjeras en Argentina, no reconociéndolas ${ }^{89}$. Los vínculos entre ciertas logias de élite y la Unión Industrial Argentina parecen probables; en cualquier caso, el senador Miguel Cané, promotor de la ley de residencia era masón desde $1872^{90}$.

Pero las presiones al Gran Oriente Ibérico, en territorio argentino, no solo provinieron de instituciones rivales. A mediados de 1897, bajo el título de Los Secretos de la Masonería: Sus palabras, toques, señales, formas de darlas y fines que persigue, circuló un folleto antimasónico impulsado por el arzobispo de Buenos Aires que revelaba el contenido de un documento oficial de la secretaría de la Gran Logia Simbólica Española, que contenía las palabras secretas del rito de Villarino ${ }^{91}$. Uladislao Castellano, tercer arzobispo de Buenos Aires, con el fin de debilitar a la masonería se había aliado al ex masón grado 33 Miguel Pérez López, expulsado del Gran Consejo Ibérico, para divulgar las doctrinas y secretos de la asociación española, obligando a ésta a adoptar medidas

\footnotetext{
${ }^{88}$ Presidencia de la Nación, Ministerio de Justicia, Seguridad y Derechos Humanos, Secretaría de Derechos Humanos, De la Ley de Residencia al Terrorismo de Estado: La actividad represiva del Estado ante los movimientos sociales emergentes durante el siglo XX (Buenos Aires: Archivo Nacional de la Marina, 2009), 7.

${ }^{89}$ Art. 165 de la Constitución del Supremo Consejo y Gran Oriente de la República Argentina reformada en 1895: "La Masonería Argentina no reconoce las logias establecidas o que se establezcan en el territorio de la Republica bajo la dependencia de Orientes Extranjeros".

${ }^{90}$ Mollés, “¿Derecha o Izquierda? El anticlericalismo argentino frente a la cuestión social (1904-1910)”, Travesía, revista de historia económica y social 14-15 (2014): 261-262.

${ }^{91}$ Pérez López, Miguel, Los Secretos de la Masonería: Sus palabras, toques, señales, formas de darlas y fines que persigue (Buenos Aires: Pérez \& Serrano, 1897), 36-37.
} 
extraordinarias y declarar que la Argentina estaba en estado anormal y perturbador para la masonería ${ }^{92}$.

Finalmente, los talleres del Gran Consejo General Ibérico en Argentina desaparecerán o serán captados por otras asociaciones, al comenzar el siglo XX. Debilitada, la Gran Logia Bonaerense, por las múltiples presiones del Gran Oriente de la Republica con la intención de desposeerla de sus logias bonaerenses, y por el aislamiento en que se encontraba su institución patrocinante desde 1897, sucumbió hacia el año 1900, reduciendo su influencia y sus talleres solamente a la ciudad de La Plata ${ }^{93}$.

\section{Conclusión}

El federalismo argentino llevó a que la provincia de Buenos Aires funde una nueva capital, en un intento de diferenciarse de la vieja y congestionada metrópolis. La Plata, ciudad planificada como una urbe del futuro, fue poblada por extranjeros de clase obrera y burguesa que trajeron consigo costumbres del viejo mundo, que con los hábitos locales formaron una peculiar raigambre que caracterizó a esta urbe durante décadas. Estando dentro de esta amalgama cultural las costumbres de la masonería.

Una de las preguntas que se suscitan es: ¿los ideales con que fueron planificadas todas las características de la nueva capital, influyeron en sus pobladores? Todo indicaría que sí, y que ello se filtró a sus instituciones y asociaciones. Los primeros habitantes tenían bien en claro que vivían en una "ciudad modelo" nacida para competir con Buenos Aires, su puerto y sus instituciones, donde las progresistas autoridades de la provincia, que se había convertido en la más adelantada de Sudamérica en materia educativa, destinaban palacios, no solo para los poderes públicos, sino también para las escuelas de su capital. Y donde la religión estaba en un plano secundario.

Casualidad o no, el declive de la institución masónica en 1897 coincide con la fundación de la tan postergada Universidad Provincial y posterior Universidad Nacional de La Plata. Lo que no fue casualidad es que esta universidad se convirtió en la máxima creación del positivismo en la educación argentina, siendo fundada sobre la base de la investigación científica, que tendió a reemplazar la tradicional clase informativa por las clases prácticas en la que profesores y alumnos se caracterizarán por utilizar métodos experimentales. Y convirtiéndose en la más progresista en el periodo anterior a la reforma universitaria de 1918. ¿Otra institución vanguardista producto de una ciudad racional?

\footnotetext{
${ }^{92}$ BP-GCGI-GLSE 4, “A.U.T.O.S.A.G.” (1897): 5.

${ }^{93}$ Existen indicios de que pudo estar activa hasta la muerte de Santa Olalla en 1909, para luego ser refundada por el masón español José Moser Giner y otros, con el rito escocés antiguo y aceptado. Finalmente, las autoridades de la Gran Logia Bonaerense deciden disolverla en año 1926, aconsejando a sus logias incorporarse al Gran Oriente Español en Argentina. Extraído de CDMH. Salamanca. José Moser Giner. Leg. 17 Exp. 13.
} 
De lo expuesto, no puede dejar de resaltarse que las motivaciones de ambas asociaciones coincidían en la educación de las clases bajas; sin embargo, el rito alternativo y las reformas en Argentina estaban orientadas hacia la secularización de la masonería, ante un supuesto avance clerical y ante las políticas progresistas del Estado argentino en materia educativa; mientras que en España obedecía a una adaptación a la realidad social española y las injusticias sociales de un Estado indiferente, debido a los vínculos de la asociación con el Partido Republicano Español.

El Gran Consejo General Ibérico y su máxima autoridad Isidro Villarino, claudicando al orientalismo egipcio y las doctrinas metafísicas que se desprendían de éste, recurrieron a la simpleza y racionalidad del sistema masónico de la Gran Logia Bonaerense, buscando lo que buscan las ciencias positivas, es decir la experiencia directa con resultados concretos.

La asociación bonaerense nunca logró imponer en la masonería argentina su rito, como ya hemos visto, porque fue víctima de la reacción conservadora de fines de siglo; sin embargo, su idea de que la enseñanza en sus distintas fases debía estar regulada por una sola institución pedagógica, fue concretada por otros masones en los primeros años del nuevo siglo ${ }^{94}$.

\section{Fuentes}

Archivo Histórico de la Provincia de Buenos Aires (AHPBA). La Plata, Argentina.

Centro Documental de la Memoria Histórica (CDMH). Salamanca, España.

Boletín de Procedimientos del Soberano Gran Consejo General Ibérico y la Gran Logia Simbólica Española, Madrid. (1889-1898).

Revista Masónica: Órgano Independiente de la Masonería Universal. Buenos Aires (18941904).

Boletín Oficial de la Confederación de Lojias Unidas, "Causa de ser de la Gran Logia Provincial Bonaerense", La Plata (1891).

Las Dominicales del Libre Pensamiento, "Los frailes en La Plata”, Madrid (1886).

La Capital, "Liceo de La Plata", La Plata (1888).

El Día, "Cámara de Senadores", La Plata (1889).

La Vanguardia, “Almanaque del Trabajo”, Buenos Aires (1920).

\footnotetext{
${ }^{94}$ La actual Escuela Graduada “Joaquín V. González” de La Plata fue creada por decreto del Poder Ejecutivo Nacional del 24 de enero de 1906. Con su creación se completó el proceso educativo dentro de la universidad. Por primera vez en el país se lograba, como pretendía el masón y presidente de la Universidad de La Plata, Joaquín V. González, la armonía y continuidad de las distintas etapas de la enseñanza primaria, secundaria y universitaria, bajo una sola institución educativa. La escuela surgió como anexa a la Sección Pedagógica de la Facultad de Ciencias Jurídicas y Sociales de la Universidad Nacional de La Plata, que se encontraba a cargo de otro distinguido masón platense, el profesor Víctor Mercante.
} 


\section{Bibliografía}

Álvarez Lázaro, Pedro. "Pluralismo masónico en España”. En La Masonería en la España del siglo XIX. Coordinado por José Antonio Ferrer Benimeli. Zaragoza: CEHME, 1987.

Arrondo, César. "Arquitectos y soñadores en los origenes de la ciudad de La Plata". En Nueva historia de las redes masónicas atlánticas: 200 años de relaciones masónicas entre Argentina, Uruguay, Chile y Francia. Coordinado por Dévrig Mollés. La Plata: Edulp, 2012.

Barrancos, Dora. Educación, cultura y trabajadores (1890-1930). Buenos Aires: Centro Editor de América Latina, 1991.

De Lucia, Daniel Omar. "La tradición laica en la ciudad universitaria: El movimiento librepensador en La Plata (1896-1919)". En La Universidad de La Plata y el Movimiento Estudiantil: Desde sus orígenes hasta 1930. La Plata: Edulp, 1999.

Enríquez del Árbol, Eduardo, “Al filo de un centenario: El último Gran Oriente Hispano del

siglo XIX: La Gran Logia Simbólica Española del Rito Primitivo y Oriental de Memphis y Mizraim (1889-1989)". En Masonería, Revolución y Reacción. Coordinado por José Antonio Ferrer Benimeli. Zaragoza: CEHME, 1990.

Enriquez del Árbol, Eduardo. "La Injusticia social en la prensa masónica de fines del siglo XIX: El Boletín de Procedimientos del Gran Oriente Ibérico". En REHMLAC+ 7 no.

1 (mayo-noviembre 2015 [citado el 12 de marzo de 2017]): disponible en http://revistas.ucr.ac.cr/index.php/rehmlac/article/view/19945/20101

Enriquez del Árbol, Eduardo. "El mundo obrero de la prensa masónica: El $1^{\circ}$ de mayo de 1890 en el Boletín de Procedimientos del Gran Oriente Ibérico". En REHMLAC+ 8, no. 1 (mayo-noviembre 2016): doi: http://dx.doi.org/10.15517/rehmlac.v8i1

Escolano Benito, Agustín. "Las Escuelas Normales, siglo y medio de perspectivas históricas". Revista de ciencias de la educación: Órgano del Instituto Calasanz de Ciencias de la Educación 157 (1994): 55.

Gandolfi, Fernando y otros. "Los ámbitos de la memoria: Liceo Víctor Mercante". En Ambiente, revista de arquitectura, urbanismo y planificación. La Plata: CEPA, 1989.

Lappas, Alcibiades. La Masonería Argentina a través de sus hombres. Buenos Aires: Lappas Alcibiades, 1966.

Mollés, Dévrig. "Exiliados, emigrados y modernizadores: el crisol masónico euro-argentino (Europa-Rio de la Plata, 1840-1880)". En La masonería española en la época de Sagasta. Coordinado por José Antonio Ferrer Benimeli. Zaragoza: CEHME, 2007.

Mollés, Dévrig. "Un puente transatlántico: La Gran Logia Filial Hispano-Argentina del Grande Oriente Español”. En La circunstancia euro-americana de Entre-Guerras. Coordinado por José Antonio Ferrer Benimeli. Zaragoza: CEHME, 2007. 
Mollés, Dévrig. “¿Derecha o Izquierda? El anticlericalismo argentino frente a la cuestión social (1904-1910)". En Travesía, revista de historia económica y social 14-15 (2014): 261-262.

Rodríguez Lettieri, María Elena. "La masonería española en la República Argentina (18901930)”. En La masonería española en la época de Sagasta. Coordinado por José Antonio Ferrer Benimeli. Zaragoza: CEHME, 2006.

Salvadores, Antonio. Fundación de la Ciudad de La Plata: Documentos éditos e inéditos. Publicaciones del Archivo Histórico de la Provincia de Buenos Aires. Tomo VIII. La Plata, 1932.

Salvadores, Antonio. "La nueva ciudad". En Ambiente, revista de arquitectura, urbanismo y planificación. Edición especial. La Plata: CEPA, 1989.

Santa Olalla, Enrique. El Instructor del Rito Ecléctico. La Plata: Gran Logia Regional Bonaerense, 1894.

Solari, Manuel. Historia de la Educación Argentina. Buenos Aires: Paidos, 1987.

Vedoya, Juan Carlos. Historia de la Instrucción Primaria en la República Argentina. Tandil: Universidad Nacional del Centro de la Provincia de Buenos Aires, 1984.

Vidaurreta, Alicia. "Luis Ricardo Fors Librepensador y Bibliógrafo". En Redescubriendo un continente: La inteligencia española en el París Americano en las postrimerías del siglo XIX. Compilado por Hugo Biagini. Sevilla: Diputación Provincial, 1993. 